\title{
EL PROCESO DE EXPROPIACIÓN DE LA BIBLIOTECA DE LOS JESUITAS EN PAMPLONA (1767-1774)
}

\author{
JAVIER VERGARA
}

U.N.E.D.

\section{DISPOSICIONES REGIAS SOBRE LIBRERÍAS JESUÍTICAS}

A la expulsión de España de la Compañía de Jesús siguió una fiebre obsesiva por inventariar los bienes de los llamados a partir de entonces jesuitas expulsos. Una parte muy importante de ese proceso iba a afectar de forma muy temprana a los libros y papeles existentes en las 147 casas y colegios que la Compañía tenía en tiempos de su extrañamiento. Material importante para la Corona con el cual no sólo se pretendía complementar las bibliotecas de las universidades y seminarios del reino, sino encontrar argumentos que justificasen, por un lado, la expulsión misma y, lo que quizá era más innoble y doloroso, hacer un inventario de propiedades y libros que sufragase, con su posterior venta, parte de los costes de expulsión y otras necesidades del gobierno carolino.

El proceso de catalogación e inventario de libros y papeles tuvo dos partes: una primera, que podríamos considerar introductoria, en la que aparecen disposiciones generales que incluyen aspectos referidos a archivos, libros y bibliotecas; $y$, una segunda, específica, en la que se legisla ex profeso sobre el tema. En la primera parte cabe citar especialmente el punto VI de la Instrucción de lo que deberán ejecutar los comisionados para el extrañamiento y ocupación de bienes, firmada por el ínclito Aranda un mes antes de la expulsión, concretamente el 1 de marzo de 1767. En ella ya se prescribe que:

«Hecha la intimación, (se) procederá sucesivamente, en compañía de los padres Superior y Procurador de la Casa, a la judicial ocupación de archivos, papeles de toda especie, biblioteca común, libros y escritorios de aposentos, distinguiendo los que pertene- 
cen a cada jesuita, juntándolos en uno o más lugares, y encargándose de las llaves el Juez de la Comisión» ${ }^{1}$.

Estaba claro desde el principio que los papeles y libros constituían para los Aranda y un largo etcétera de ilustrados antijesuitas una obsesión de base irrenunciable. En ellos pensaban encontrar algunas de las claves ocultas que justificasen no sólo su oposición a la Compañía sino incluso su misma expulsión. Por eso no es extraño que el fiscal Campomanes incitara con cierta ansiedad a que se recogieran «legajos separados, sin omitir papel alguno por inútil y despreciable que parezca; pues todos se deben recoger y ordenar con el mayor cuidado $»^{2}$. El responsable de ejecutar inicialmente esa tarea debía ser un comisionado, nombrado al efecto por el Presidente del Consejo - entiéndase Aranda - Su labor consistiría en impulsar y coordinar no sólo el inventario de libros y manuscritos, sino todos los bienes, efectos y propiedades jesuíticas con vistas a su posterior reutilización. En esa tarea se podría contar con el Procurador de cada colegio, al que se le retrasaría por dos meses su expulsión, situándole en la indecente e ingrata humillación de colaborar obligatoriamente en la expropiación de sus propias temporalidades ${ }^{3}$.

Para que esta tarea fuese eficaz la Corona planteó una segunda fase de legislación concreta y específica. Etapa que estuvo jalonada por cuatro disposiciones llamadas a regular uno de los procesos de expropiación de libros más importantes de la historia de este país. La primera disposición al respecto, que sirvió de base a todas las demás, fue una Real Cédula, fechada el 22 de abril de 1767, sólo 20 días después de la Pragmática Sanción de extrañamiento. Su mentor, Campomanes, proponía «un método individual de formalizar el Índice, y reconocimiento de Libros y Papeles de las Casas de la Compañía, por requerir reglas especiales para que se ejecutase con uniformidad en todas ellas, y con el debido método, distinción y claridad» ${ }^{4}$. El método trascendió con creces sus objetivos expropiatorios y se convirtió en un referente temprano de la normalización descriptiva de los libros españoles, amén de ser un modelo reconocido de biblioteconomía internacional. Las colecciones bibliográficas expropiadas por la Revolución francesa siguieron en buena parte los criterios de catalogación prescritos por Campomanes ${ }^{5}$.

La Instrucción constaba de 24 puntos, orientados a regular dos grandes objetivos: conformar un sistema de información bibliográfica uniforme y preservar los fondos para un destino que inicialmente se presentaba indefinido. Al primero de los aspectos se dedicaron los cinco primeros puntos. En el primero se mandaba expresamente ela-

1. Colección general de providencias sobre el extrañamiento y ocupación de temporalidades de la Compañia de Jesús por Carlos III. Madrid, Imprenta Real, 1774. Parte primera, pp. 6-14.

2. Ibidem, p. 69.

3. Ibidem, pp. 56-57.

4. Ibidem, pp. 65-73.

5. Alonso Miguel, A. (2003). El sistema clasificatorio de las bibliotecas de la Compañía de Jesús y su presencia en la bibliografía española. En VERGARA CiORDIA J., Estudios sobre la Compañía de Jesús: los jesuitas y su influencia en la cultura moderna (S. XVI-XVIII). (p. 399) Madrid, UNED-Ediciones. 
borar dos tipos de inventarios: uno perteneciente a material manuscrito, otro a material impreso, «expresando el tamaño de marca mayor, folio, cuarto u octavo». Los puntos II y III fijaban que el inventario de impresos recogiera el apellido del autor, el nombre propio entre paréntesis, el título, el lugar y el año de edición. El punto IV, que se refería al modo de inventariar los papeles manuscritos, prescribía que se recogiese «los dos primeros renglones con que comienza la obra y los dos últimos con que finaliza, y el número de folios de que consta». Dentro de estos documentos debían incluirse los «Códices membranáceos, en letra gótica, o monacal antigua (...) expresando al efecto si se hallan escritos en vitela» (Punto V).

La segunda parte, de carácter más indefinido, se sustanciaba sobremanera en los puntos VIII, XIV, XVI y XIX. Por el primero, se prescribía que, amén del catálogo general, se hiciese un inventario particular de cada uno de los aposentos y estancias de la casa, donde a buen seguro habría tantos o más libros que en la biblioteca general. El punto XVI recomendaba que fuese hecho por libreros hábiles de la ciudad, que añadirían una tasación aproximada de cada libro, y por «algún literato inteligente» que debía velar por la correcta y exacta ortografía de los índices. El punto XIX hacía referencia a las librerías existentes en los colegios. Se trataba de una figura, ubicada habitualmente en las «Porterías» colegiales, con un fin claro y específico: la venta y distribución de obras, esencialmente jesuíticas, pensadas para cubrir las necesidades pastorales, misionales y académicas de los colegios. Tal era su importancia que se prescribió que se hiciera un «inventario, con expresión de los ejemplares en papel, o encuadernados, que se encontraren, y el precio a que se vendía cada tomo, o juego, para darles salida, como caudal y efectos de la misma Casa». Finalmente, le punto XXIV sugiere la posibilidad de agregar todos estos libros a las bibliotecas universitarias.

A esta primera disposición, pensada sobre todo para los libros y papeles impresos, siguió una segunda de ocho puntos, firmada el 29 de julio de 1767, y orientada a preservar todo lo concerniente a papeles manuscritos. En ella se perfilaban tres aspectos que a la Corona interesaba salvaguardar: los papeles relativos a las haciendas, diezmos, cuentas y caudales de cada casa; los papeles que trataban de asuntos políticos, satíricos y de las expulsiones de Francia y Portugal; y finalmente todo lo concerniente a la correspondencia privada, a las cartas de Generales y a la mantenida con obispos ${ }^{6}$. Material que, en atención a una circular enviada a los comisionados, el 2 de mayo de 1769, debía remitirse al Colegio Imperial para su estudio y clasificación ${ }^{7}$. La Corona pretendía encontrar aquí las razones últimas que le faltaban para justificar pública y socialmente la expulsión. Una medida que, a pesar del calado y trascendencia que conllevaba, debía estar exenta de toda crítica o sátira social. A los responsables les iba en ello no sólo la confiscación de bienes sino incluso la propia vida ${ }^{8}$.

6. Colección general de providencias... Parte primera, pp. 113-119.

7. Ibidem. Parte II, pp. 141-142.

8. Ibidem. Parte IV, p. 50. 
Una tercera circular, aparentemente de menor entidad, fue una disposición firmada por Carlos III el 17 de diciembre de 1770 para decidir el destino definitivo de los fondos jesuíticos. Un tema que desde el principio había generado dudas y problemas. Para unos, las universidades y seminarios debían ser las receptoras de los libros jesuíticos; para otros, su venta parecía el destino adecuado. Ventura Figueroa, colector general interino de expolios y vacantes, zanjó el asunto fijando un Reglamento que prescribía que los fondos jesuíticos no fuesen vendidos sino entregados a los prelados y sucesores para el aprovechamiento público de sus diocesanos. Acuerdo que, el 4 de enero de 1771, se remitía al conde de Aranda, Presidente del Consejo, para que procediera a su rápida ejecución'.

No iban, sin embargo, a suceder los acontecimientos tal como estaba previsto. El propio Aranda retrasó su ejecución de manera consciente, achacando al Reglamento de Ventura Figueroa una manifiesta generalidad, especialmente en lo que se refería a la no distinción entre papeles impresos y manuscritos. Cuestión importante para los mentores de la expulsión, pues muchos documentos, especialmente papeles manuscritos y de disciplina interna de los expulsos, trascendían el interés bibliográfico para enmarcarse en intereses ideológicos y políticos que interesaban a la Corona. La situación era de tal calado que Aranda, por boca de Campomanes, pidió expresamente, el 27 de agosto de 1771, que de la documentación a entregar a los diocesanos se excluyese expresamente todo lo relativo a papeles manuscritos y de disciplina exterior e interior - tal como prescribía la circular de 2 de mayo del 69-. El 29 de octubre de 1771 Carlos III daba el visto bueno a dicha petición y el 5 de febrero de 1772 mandaba que se hiciera una Real Provisión, que fue definitivamente firmada el 2 de mayo de $1772^{10}$.

Esta cuarta disposición, que cerraba el cupo carolino sobre el destino último de los libros y bibliotecas jesuíticas, era en realidad el reglamento de Ventura Figueroa con pequeñas adiciones. Entre sus puntos importantes sobresalen la decisión de no entregar a los diocesanos las bibliotecas de los colegios de Loyola y Villagarcía de Campos, que debían reservarse para constituir dos seminarios de misiones. Lo mismo se pedía para los colegios ubicados en ciudades donde había universidad de nueva creación. Sus fondos se destinarían a enriquecer las bibliotecas de las nuevas universidades. También se acordó no entregar a los prelados las bibliotecas del colegio de Toledo y las de los dos colegios de Palma de Mallorca. Sus fondos se reservarían para el futuro seminario tridentino toledano y para la antigua universidad de la Isla, que aunque no era de nueva creación era de sumo interés mantenerla por ser la única de la Isla. El resto podría reservarse a los palacios episcopales para uso público de los diocesanos. La Real Provisión termina haciendo a los comisionados dos advertencias: primero la absoluta necesidad de que los papeles manuscritos y los referidos a la disciplina interior y exterior se remitiesen definitivamente al Archivo de San Isidro el Real de Madrid, quedando a disposición del Director de los Estudios Reales, de sus biblio-

9. Ibidem. Parte IV, pp. 39-46.

10. Archivo Diocesano de Pamplona (A.D.P.). Caja 277, $\mathrm{N}^{\circ} 4$. 
tecarios y oficiales de Contaduría, a quienes se comunicaría la orden correspondiente para su estudio y custodia; en segundo lugar se recordaba la necesidad ineludible de retirar los libros de la llamada «escuela jesuítica» y aquellos que contuviesen máximas y doctrinas perjudiciales al dogma, religión, buenas costumbres y regalías de S. M. «Los cuales han de quedar separados en las mismas bibliotecas episcopales y en las universidades y seminarios» ${ }^{11}$.

\section{INVENTARIO DEL COLEGIO PAMPLONÉS}

La expropiación, catalogación e inventario de libros y papeles existentes en el colegio jesuítico de la Anunciada de Pamplona siguió el proceso de ejecución y temporalización marcado por los avatares de las cuatro disposiciones anteriores. Un proceso largo y complejo que se inició en 1767 y concluyó definitivamente en 1774. En esos años el proceso pasó por cinco etapas distintas: la catalogación de obras venales, el inventario de manuscritos, el de aposentos, el inventario de la librería común y el de su entrega definitiva al obispado. Veamos a continuación cómo fueron las circunstancias de cada una de estas etapas y el destino último de los documentos.

\section{a) Obras venales}

La catalogación e inventario de libros venales del colegio pamplonés la puso en marcha, el 26 de mayo de 1767, José Contreras, regente que fue del Consejo Real de Navarra y primer Juez Comisionado en la ocupación de temporalidades. Ese día, atendiendo a las prescripciones del punto XIX de la Real Cédula de 22 de abril de 1767 - que prescribía la catalogación de obras venales existentes en las porterías de los colegios-, y sobre todo movido por la carta circular de 30 de abril de 1767, que incitaba a los comisionados a informar sobre los bienes que habían quedado en las casas de los expulsos ${ }^{12}$, encargaba a Benito Coscuyuela, mercader e impresor de libros de Pamplona, realizar, con la inspección y ayuda del P. Francisco Belza, regente de estudios del convento de San Agustín de Pamplona, el índice y tasación de los libros venales del colegio pamplonés ${ }^{13}$.

La tarea no resultaba baladí en el marco contextual de un colegio como el de Pamplona. Un colegio que si bien no poseía imprenta propia sí desplegaba una actividad extraordinaria relacionada con la producción, edición, venta y distribución de libros. Dos hechos explicaban sobremanera esa situación: por un lado, la importante red comercial de impresores y libreros que había en Navarra $^{14}$, red que desde el primer

11. Colección general de providencias... Parte cuarta, p. 42-46.

12. Ibidem. Parte primera, pág. 73.

13. Archivo Histórico Nacional [A.H.N.]. Clero, jesuitas, legajo 673, $\mathrm{N}^{\mathrm{o}}$ 7. Expediente de temporalidades de Pamplona sobre administración de los bienes y efectos de los mismos, sobre libros encontrados en el colegio.

14. Sobre este tema véase, entre otros, los siguientes trabajos: ARIGITA Y LASA, M. (1901) Bibliografia navarra, descripción de las obras impresas en este antiguo reino desde el descubrimiento del arte tipográfico 
instante se puso al servicio de los jesuitas haciendo innecesaria la creación de una imprenta colegial; por otro, una más que notable proyección apostólica que trascendía con mucho las labores docentes colegiales para canalizarse en sermones, homiliarios, misiones populares, doctrinas, congregaciones, ejercicios, etc. que exigían una producción continua e importante de libros.

Si repasamos los libros de cuentas del siglo XVII observamos cómo cantidades importantes de dinero se destinaban a la compra, venta, encuadernación y distribución de libros. En 1617, por ejemplo, se pagaban 88 reales por la compra de un San Bernardo y un Cornelio encuadernados; en noviembre de 1628 se llegaron a pagar 403 reales por una partida de libros que se tomaron del P. Matienço ${ }^{15}$. En el siglo XVIII las cantidades aumentaron considerablemente. En 1725, el P. Reigadas concertaba con el librero José Botaya entregarle un porcentaje del 15 por ciento por cada libro de misiones vendido ${ }^{16}$; en no pocas ocasiones los libros se producían y vendían desde la propia casa y en otros casos se traducían. En 1744, por ejemplo, el colegio pagaba la impresión de 1500 Vidas de Cristo del P. Dutari, traducidas al vascuence, junto a mil novenas de a pliego, que importaban un total de 556 reales $^{17}$. En la misma línea, se entregaban al P. Zuimendi tres juegos de diccionarios en vascuence, junto con 100 Meditaciones del italiano Juan Pedro Pinamonte, 40 Kempis en romance y 300 Ejercicios de San Ignacio ${ }^{18}$.

Toda esta actividad deja traslucir que colegios como el de Pamplona tenían una importantísima labor de producción, venta y distribución de libros. Labor que la expulsión se encargó de abortar, no sin antes dejar en la librería colegial una importante cantidad de libros venales que Coscuyuela se encargó de inventariar y tasar. El resultado de su trabajo se muestra en la siguiente lista:

\section{Ejemplares}

125 ejemplares

73 ejemplares

25 ejemplares

129 ejemplares

76 ejemplares

22 docenas

31 ejemplares

Otros tantos

27 ejemplares

\section{Tamaño Título}

fol. Historia del Corazón de Jesús

fol. Vida de San Carlos Borromeo

fol. Vida de San Francisco de Sales

$8^{\circ} \quad$ Vida del Venerable Juan Bermans

$8^{\circ} \quad$ Historia del Corazón de Jesús

San francisco Javier

$8^{\circ} \quad$ Quinto Curcio

$8^{\circ} \quad$ Ovidio

$8^{\circ} \quad$ Selectas
Precio

6 Rs

8 Rs

6 Rs

$1 \mathrm{R}$

$1 \mathrm{R}$

$1 \mathrm{R}$ docena

$15 \mathrm{Rs}$

$15 \mathrm{Rs}$

$1 \mathrm{R}$

hasta nuestros días. Pamplona, Imprenta provincial. PÉREZ GOYENA, A. Ensayo de bibliografia navarra: desde la creación de la imprenta en Pamplona hasta el año 1910. Pamplona, Institución Príncipe de Viana., 1947-1964. Institución Príncipe de Viana, (1974) La imprenta en Navarra. Pamplona, Diputación Foral e Navarra.

15. A.H.N. Clero, jesuitas, libro 175. Libro de gasto del Colegio de la Compañia de Jesús de Pamplona. Años 1617 a 1629.

16. Biblioteca de la Real Academia de la Historia (B.R.A.H.) 11-10-3/28. Cuentas inútiles a un criado. P. Reigadas. Legajo 3, $\mathrm{N}^{\mathrm{o}} 7$. fol. 25.

17. Ibidem, $26 \mathrm{r}$.

18. Ibidem. 29 r. 


$\begin{array}{llll}22 \text { ejemplares } & 8^{\circ} & \text { Amicitia (Cicerón) } & 1 \mathrm{R} \\ 28 \text { Virgilios } & 8^{\circ} & \text { (sin pergamino) } & \text { A sueldo } \\ 46 \text { ejemplares } & 8^{\circ} & \text { Sánchez: Elegancia formal } & 1 \mathrm{R} \\ 40 \text { ejemplares } & 4^{\circ} & \text { Colecciones teológicas } & 1 / 4 \mathrm{de} \mathrm{R} \\ 92 \text { practacas } & 8^{\circ} & \text { Industrias } & 12 \mathrm{Mrs} \\ 13 \text { ejemplares } & 4^{\mathrm{o}} & \text { Tesauros de Requejo } & 4 \mathrm{Rs} \\ 4 \text { ejemplares } & \text { fol. } & \text { De las Doctrinas } & 8 \mathrm{Rs} \\ 43 \text { ejemplares } & 4^{\circ} & \text { De compras y ventas } & 2 \mathrm{Rs} \\ 46 \text { ejemplares } & 4^{\mathrm{o}} & \text { Generatione et anima del P. Losada } & 4 \mathrm{Rs} \\ 45 \text { ejemplares } & 4^{\circ} & \text { Física del P. Losada } & 4 \mathrm{Rs} . \\ 16 \text { ejemplares } & 4^{\mathrm{o}} & \text { Lógica del P. Losada } & 4 \mathrm{Rs} \\ 134 \text { ejemplares } & 4^{\circ} & \text { Institutiones dialecticae del P. Losada } & 1,5 \mathrm{Rs} \\ 94 \text { ejemplares } & 8^{\circ} & \text { Institutiones dialecticae del P. Losada } & 1 \mathrm{R} \\ 100 \text { ejemplares } & 8^{\circ} & \text { Historia del Corazón de Jesús } & 24 \mathrm{Mrs} \\ 29 \text { ejemplares } & 8^{\circ} & \text { Historia del cielo empireo } & 24 \mathrm{Mrs} \\ 10 \text { ejemplares } & 8^{\circ} & \text { Vida del Padre Dutari } & 1 \mathrm{R} \\ 19 \text { ejemplares } & 8^{\circ} & \text { Corazón de Jesús, de Peñalosa } & 1 \mathrm{R} \\ 15 \text { juegos } & & \text { Otaiz garae, por el P. Mendiburu } & 12 \mathrm{Rs} \\ 190 \text { juegos } & & \text { Otaiz garae, por el P. Mendiburu } & 9 \mathrm{Rs} \\ 3 \text { juegos } & 8^{\circ} & \text { Del mismo tema, por el P. Mendiburu } & 16 \mathrm{Rs} . \\ 80 \text { juegos } & & \text { Del mismo tema, por el P. Mendiburu } & 11 \mathrm{Rs} \\ 20 \text { ejemplares } & 8^{\circ} & \text { Devociones (Vascuence), P. Mendiburu } & 24 \mathrm{Mrs} \\ 239 \text { ejemplares } & 16^{\circ} & \text { Devociones (Vascuence), P. Mendiburu } & 12 \mathrm{Mrs} \\ 456 \text { reglas } & 12^{\circ} & \text { Congregación del Corazón de Jesús } & 9 \mathrm{Mrs} \\ 19 \text { ejemplares } & 8^{\circ} & \text { Vida del Padre Lapuente } & 1,5 \mathrm{Rs}\end{array}$

La suma de todos estos libros suponía un total de 2211 volúmenes, con un precio estimado que superaba los 4550 maravedíes. Buena parte de esos libros se vendió y el resto se incorporó a la biblioteca común. Cifras a las que habría que añadir 1133 volúmenes que no fueron tasados por Benito Coscuyuela y sí enviados al Colegio Imperial de Madrid, el 5 de febrero de 1769. Los libros en cuestión fueron los siguientes:

- 125 tomos en folio de la Historia del Corazón de Jesús

- 76 tomos en $8^{\circ}$ de la Historia del Corazón de Jesús

- 22 docenas de novenas a San francisco Javier

- 4 tomos en folio de las Doctrinas

- 43 tomos en $4^{\circ}$ De compras y ventas

- 100 tomos en $8^{\circ}$ de la Historia del Corazón de Jesús

- 29 tomos en $8^{\circ}$ de la Historia del cielo empíreo

- 19 tomos en $8^{\circ}$ del Corazón de Jesús, de Peñalosa

- 20 tomos en $8^{\circ}$, Devociones (Vascuence), P. Mendiburu

- 239 tomos en $16^{\circ}$, Devociones (Vascuence), P. Mendiburu

- 456 reglas en $12^{\circ}$, Congregación del Corazón de Jesús ${ }^{19}$.

19. A.H.N. Clero, jesuitas, legajo 673, $\mathrm{N}^{\circ} 7$. 


\section{b) Inventario de manuscritos}

Paralelamente al inventario de libros venales hubo de procederse a inventariar los libros, papeles y documentos depositados en los aposentos y librería del colegio. Fue su responsable el Juez de Temporalidades, José Contreras, quien en una carta enviada al conde de Aranda, el 5 de agosto de 1767, comentaba que, una vez terminado el inventario de casas, censos, tierras, etc. procedió, de acuerdo con la disposición de Campomanes, de 22 de abril de 1767, a inventariar los libros y papeles manuscritos del colegio de los expulsos. La labor la llevaron a cabo los ya citados Benito Coscuyuela, mercader de libros, y el P. Francisco Belza, prefecto de estudios del Convento de San Agustín de Pamplona y coordinador e inspector de todo el proceso. Contreras terminaba su carta diciendo que Coscuyuela invirtió en su trabajo desde el 4 de mayo hasta el 28 de julio. Fueron en total 86 jornadas laborales, remuneradas a 4 reales por día trabajado, montando un total de 344 reales, según libranza general despachada el 19 de enero de 1768 por José Lanciego, nuevo Juez Comisionado ${ }^{20}$.

El librero Coscuyuela hizo su labor con celo. Procedió en primer lugar a inventariar los papeles manuscritos que halló en la librería común y en los aposentos. Para realizar su labor contó con dos prescripciones legales: la real cédula de Campomanes, citada anteriormente, y la Circular del Consejo Extraordinario de 29 de julio de 1767, que prescribía expresamente inventariar todo lo que concernía a tres temas: rentas, diezmos y propiedades; correspondencia manuscrita con Roma y obispos; y, finalmente, papeles que trataban de asuntos políticos, satíricos y de las expulsiones de Francia y Portugal. Como se sabe, en ello no había sólo intereses económicos. La Corona hizo de los manuscritos un icono del esoterismo jesuítico, pensando encontrar en ellos la justificación última de la expulsión.

A tal grado llegó su obsesión que incluso ningún particular debía conservar manuscrito alguno relacionado con la Compañía. Significativa fue al respecto la actitud servicial del reiterado juez Contreras que, en atención a una orden del Conde de Aranda, de 11 de abril de 1767, puso varios edictos en Pamplona, Tafalla y resto de cabezas de Merindad, conminando a «personas tenedoras en confianza o de otra suerte de caudales o material impreso o manuscrito de la Compañía a manifestarlo, pena de confiscación de bienes y el ejemplar castigo que corresponde si por los libros o papeles se descubre su ocultación». Prescripción que además era «extensiva a terceras personas que tuvieren noticia que alguien tuviera pertenencias de la Compañía» ${ }^{21}$.

El edicto era de un rigor extremo, causaba temor sólo leerlo, aun así no tuvo los efectos prácticos que Madrid esperaba. En Navarra sus frutos se limitaron a siete cartas manuscritas de jesuitas que fueron entregadas por los particulares a las autoridades correspondientes. El juez Contreras las remitía a Madrid, «en un cañón de hoja de lata, rotulado a V. Excia», el 20 de junio de 1767. Correspondían a: «el Duque de Granada,

20. A.H.N. Clero, jesuitas, legajo 822, $\mathrm{N}^{\circ} 1$.

21. A.H.N. Clero, jesuitas, legajo 673, $\mathrm{N}^{\mathrm{o}} 6$. 
a Saturnino de Egura, a Francisca Ochagavía, a José Echauri, a Teresa de Lastiri, a Javier Navarro y Quijada y a Esteban de Ripalda, quedando reservados sus nombres conforme a la práctica de su Majestad $\rangle^{22}$.

¿Cuál fue el resultado de toda esta labor? Coscuyuela recogió en total 190 legajos, inventariados topográficamente, es decir por aposentos y estancias. En principio, de acuerdo a las directrices citadas de Campomanes, debía recoger sólo «los dos primeros renglones con que comienza la obra y los dos últimos con que finaliza, y el número de folios de que consta». Una prescripción que cambió en parte por un breve resumen descriptivo del contenido del manuscrito. A título de ejemplo recogemos una pequeña muestra de su inventario, tal como se recoge en los papeles conservados en la Real Academia de la Historia:

Índice de manuscritos de la Librería General.

- Cartas y papeles en orden a la vida del V. P. Jacinto de la hacienda de Tafalla no tiene más manuscritos que un legajo de cartas de correspondencia privada que se reduce a órdenes que tenia del Procurador para enviar los géneros necesarios y hacer algunas cobranzas.

- Moral. Ocho cuadernos de materias morales comunes.

- Papeles varios en ocho tomos en folio y tres en cuarto en los cuales se incluyen varias piezas históricas del uso del P. Moret y las castigaciones de la historia del P. Juan Mariana por lo perteneciente al Reino de Navarra.

Índice de manuscritos de Ignacio Uriarte.

- Apuntamientos del P. Pedro Ramírez en un tomo en folio.

- Cartas de los Padres Generales y Provinciales. Es un tomo en folio que consta de 345 y contiene a demás de lo dicho profesiones, incorporaciones votos de i...?.y recibos de la Compañía

- Carta única de correspondencia literaria.

¿Qué contenían los 190 legajos inventariados por Coscuyuela? Fuera del inventario económico podría decirse que de especial relevancia para la Corona nada de nada. Contenían sobre todo papeles relativos a la administración colegial ordinaria, a los libros de cuentas, propiedades, censos, sermones, resúmenes de obras literarias, de historia, de teología y de moral, y un sin fin de correspondencia legal y privada. En un afán de síntesis puede verse su temática en el cuadro siguiente:

22. A.H.N. Clero, jesuitas, legajo $673, \mathrm{~N}^{\circ} 6$. 


\begin{tabular}{|l|c|c|c|c|c|c|c|}
\hline & $\begin{array}{c}\text { Asunt. } \\
\text { econó. }\end{array}$ & $\begin{array}{c}\text { Papel } \\
\text { vario }\end{array}$ & $\begin{array}{c}\text { Cartas } \\
\text { oficiales } \\
\text { privadas }\end{array}$ & $\begin{array}{c}\text { Escritos } \\
\text { Hist. y } \\
\text { Literat. }\end{array}$ & $\begin{array}{c}\text { Escritos } \\
\text { Teología } \\
\text { y Moral }\end{array}$ & $\begin{array}{c}\text { Escritos } \\
\text { sermo- } \\
\text { nes }\end{array}$ & Tot. \\
\hline Librería & 1 & - & 1 & 4 & 3 & 1 & 10 \\
\hline Zarate & 1 & 1 & 1 & 1 & 1 & 1 & 6 \\
\hline Rector & 2 & 1 & 5 & 1 & 3 & 3 & 15 \\
\hline Ozcariz & - & 3 & 2 & 2 & 2 & 2 & 11 \\
\hline Mendiburu & 1 & 3 & 1 & 2 & 8 & 1 & 16 \\
\hline Solano & 1 & - & 4 & - & 6 & 1 & 12 \\
\hline Huéspedes & - & 1 & 1 & 1 & 2 & - & 5 \\
\hline Zumbil & - & 1 & 1 & - & - & - & 2 \\
\hline Procurador & 3 & 7 & 3 & 5 & 13 & 1 & 33 \\
\hline Trucios & - & 1 & 1 & - & 4 & - & 6 \\
\hline Cardaveraz & - & 1 & 1 & 1 & 2 & 1 & 6 \\
\hline Obregón & - & 1 & 1 & 3 & 3 & 1 & 9 \\
\hline Raigadas & 1 & 1 & 1 & 1 & 2 & 1 & 7 \\
\hline Aguirre & - & 3 & 1 & - & 2 & 1 & 7 \\
\hline Díaz & - & 3 & 1 & 3 & 3 & - & 10 \\
\hline Lorenzo & - & 2 & 2 & - & 2 & 2 & 8 \\
\hline Bergaz & - & 1 & 1 & 3 & 2 & 1 & 8 \\
\hline Burcet & - & 1 & 1 & - & 1 & 1 & 4 \\
\hline Ayerve & - & - & 1 & - & - & - & 1 \\
\hline Cartón & - & - & 1 & - & - & - & 1 \\
\hline Goitia & - & 1 & 1 & - & 1 & 1 & 4 \\
\hline S. Pérez & - & 1 & 1 & 1 & 1 & - & 4 \\
\hline R. Pérez & - & 1 & 1 & - & 1 & 1 & 4 \\
\hline Bandiarán & - & - & 1 & - & - & - & 1 \\
\hline TOTAL & 12 & 34 & 34 & 28 & 62 & 20 & 190 \\
\hline
\end{tabular}

¿Qué pasó con los 190 legajos? ¿Dónde se encuentran actualmente? Son preguntas cuyas respuestas están llenas de vicisitudes que comienzan con la ya citada Real Orden de 2 de mayo de 1769, que prescribía la remisión de todo material manuscrito al Colegio Imperial de Madrid. Ahí, el también conocido a partir de entonces como Archivo de Temporalidades, permaneció bajo poder estatal hasta 1815, año en que, tras ser restablecida la Compañía por Fernando VII, fue entregado bajo inventario firmado en 1816 a la entonces creada Junta de Restablecimiento. Con la segunda disolución de la Orden, acaecida el 14 de agosto de 1820, la Compañía volvió a perder el control de sus archivos, si bien pudo recuperarlos a partir de su restablecimiento el 1 de octubre de 1823. En 1834, la Compañía fue de nuevo disuelta y sus archivos, todavía concentrados en los locales de los Reales Estudios de San Isidro, comenzaron un largo y penoso peregrinaje de dispersión, perdida y deterioro. Ese año, una cantidad importante de material pasó a las dependencias de los ministerios de Hacienda y de Gracia y Justicia. 
La gran dispersión y deterioro del Archivo de Temporalidades acaeció sin embargo con la Revolución de 1868. La conocida con el nombre de «La Gloriosa» supuso la puntilla a lo mucho que todavía quedaba del Archivo de Temporalidades. Sus responsables decidieron vender a peso sus restos en el Rastro madrileño. Aunque la suerte, esta vez, se puso del lado del documento. Uno de sus principales compradores, don Francisco Javier Bravo, un indiano proveedor de los ejércitos de Paraguay y Brasil, los persiguió con tal avidez que llegó a coleccionar más de 60000 documentos. De todo ello, al Sr. Bravo le interesaba especialmente lo relacionado con la historia de América. Lo que no tenía relación lo donó, el 19 de mayo de 1872 - unos 30000 documentosal Archivo Histórico Nacional. Razón por la cual hoy puede verse parte de los mismos en los anaqueles de la Sección Clero, Jesuitas, de dicho archivo ${ }^{23}$.

El inventario manuscrito del colegio pamplonés — no sus fondos físicos-, parece que fue a parar a la partida entregada en 1834 al ministerio de Gracia y Justicia. Aunque una Real Orden del ministerio de Fomento, de 10 de julio de 1859, prescribió que los fondos jesuíticos de dicho ministerio fuesen donados a la Real Academia de la Historia. Razón por la cual el inventario de los 190 manuscritos, realizado por Coscuyuela en 1767 , se encuentra actualmente depositado en sus anaqueles ${ }^{24}$.

Qué pasó con los fondos físicos. Muchos indudablemente se han perdido, aunque una parte importante se salvó gracias a que se encontraban dentro de los 30000 documentos donados por el Sr. Bravo al Archivo Histórico Nacional. La parte que se conserva - bastante importante en relación con la que queda de otros colegios- puede verse en la Sección, Clero, Jesuitas de dicho archivo. Sección que fue inventariada en 1967 por Araceli Guglieri Navarro ${ }^{25}$.

\section{c) Inventario de libros}

La otra gran labor de Benito Coscuyuela, con la inspección del P. Francisco Belza, se centró en el inventario y catalogación de los libros impresos del colegio pamplonés. Material de todo punto importante que constituía uno de los iconos pedagógicos más importantes de la Compañía de Jesús y al que el gobierno carolino nunca quiso renunciar. Los libros expropiados estaban llamados a ser complemento documental de las universidades y seminarios de nueva creación, cuando no cimiento y base de futuras bibliotecas públicas.

«Haya librería, si se puede, general en los colegios» prescribía el artículo 372 de las Constituciones de la Compañía, y el artículo 33 de la Ratio studiorum obligaba con gravedad y contundencia a la asignación inexcusable de fondos para mantener y aumentar la biblioteca. Obligaciones graves en las que descansaba buena parte de la

23. Cfr. MAteos, F.: «El secuestro de papeles jesuíticos en el siglo XVIII, su concentración en Madrid, vicisitudes y estado actual», en introducción a GUGLIERI NAVARRo, A. (1967) Documentos de la Compañia de Jesús en el Archivo Histórico Nacional. (pp. VII-LXXXII). Madrid, Razón y Fe.

24. B.R.A.H., Jesuitas, 9/7212.

25. GUGLIERI NAVARro, A., op. cit. pp. 211-218. 
formación y puesta al día de los profesores y a las que el colegio pamplonés respondió con largueza y generosidad. En 1611, los 510 reales anuales que redituaban de un censo de 500 ducados, hechos a favor del colegio por don Juan Moreal, se asignaban en favor de la biblioteca. Censo que se mantenía vivo en tiempos de la expulsión ${ }^{26}$.

Aunque no era ésta la vía más importante de acrecentar las bibliotecas jesuíticas sino las donaciones. En 1641 el Ldo. Hurtado de la Puente, al comunicar a su amigo Rodrigo Caro la muerte del escritor Bernardo Alderete, apostillaba que los jesuitas «eran los herederos comunes de todos los libros y estudios de España» ${ }^{27}$. Con independencia del sentido hiperbólico de la frase, lo cierto es que las donaciones, bien como regalos o herencias, fueron bastante habituales. En un recorrido por los fondos jesuíticos, conservados en el Seminario Conciliar de Pamplona, puede verse una Políglota antuerpense donde se recoge una nota manuscrita en la que se lee: «Este libro con otros tres cuerpos de Biblia dio de limosna a este Colegio de la Compañía de Jesús de Pamplona el Sr. Eguía, enfermero de la Catedral de esta ciudad, y con condición que no se puedan vender y llevar». Otra herencia importante, a tenor de los varios ex libris que se encuentran de su benefactor, fue la del arcediano de la Tabla, Sr. Ibero. En libros como: Malleus Maleficarum, Lugduni, 1595; Patrum Opus Ioannis Eremita o Tertia Pars totius Summae... puede leerse que son donaciones del Sr. Ibero. Otros donantes que pueden citarse por tener varias donaciones son: el P. Gualbes, el canónigo Alcoz, el Licenciado Cruzate, Antonio Caparroso, el vicario de Eguaras, el P. Iñigo de Lodosa, el P. Alonso de Lobera y un largo etcétera que sería difícil de completar, pero que en cualquier caso pone de manifiesto que fueron las donaciones una de las vías más comunes - y quizá la más importante- de allegar fondos a las bibliotecas jesuíticas.

El resultado de todo esto fue unos fondos cercanos a los 6000 volúmenes: alrededor de 3000 pertenecían a la biblioteca común y el resto estaba diseminado por las distintas estancias y aposentos del colegio. Circunstancia que, en función del punto VIII de la real cédula de 22 de abril de 1767, obligó a realizar dos inventarios: el topográfico o de aposentos y el general o de librería común.

El inventario topográfico constituye todo un modelo de bibliografía histórica. Permite conocer con precisión qué obras disponían los moradores del colegio para su uso y lectura. Su ficha bibliográfica incluía — siguiendo a Campomanes - : apellido, nombre entre paréntesis, título, número de tomos, su tamaño, lugar de edición y la tasa del librero por reales de 36 maravedíes navarros. En los siguientes ejemplos se presenta una muestra de la labor realizada por Coscuyuela:

26. A.H.N. Clero, Jesuitas, legajo 888, cap. V.

27. Homenaje al Sr Menéndez Pelayo en el año vigésimo de su profesorado. Madrid, 1899, T. II, p. 769. 


\section{Índice de impresos del aposento del P. Pedro Xavier Zárate, $N^{\circ} 2$}

\section{Litera A}

Aguirre, (Don Agustín Ignacio); Vida de la V. Madre Tpha. del Santísimo

Alcocer, (Fr. Juan); Ceremonias de la misa

\section{Litera B}

Barcia, (Dn,. Tph); Compendio de los cinco tomos del despertador christiano

$\begin{array}{ccccc}\text { Tomos } & \text { Tamaño } & \text { Edición } & \text { Año } & \text { Tasa } \\ 01 & \text { Quarto } & \text { Pamplona } & 1724 & \begin{array}{c}01 \\ \text { Real }\end{array} \\ 01 & \text { Dozavo } & \text { Lérida } & 1612 & 9 \text { Mar. } \\ \text { Tomos } & \text { Tamaño } & \text { Edición } & \text { Año } & \text { Tasa } \\ 01 & \text { Quarto } & \text { Olite } & 1685 & 02 \text { Reales }\end{array}$

El resultado de este inventario topográfico fueron 2686 registros o títulos. Estaban repartidos del siguiente modo según las estancias de la casa:

Javier Zárate 120 títulos

Ignacio Iriarte 168

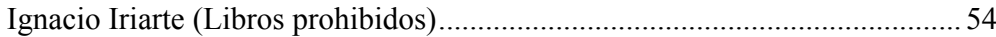

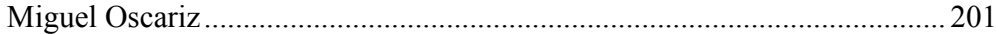

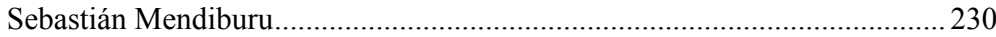

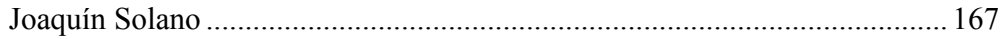

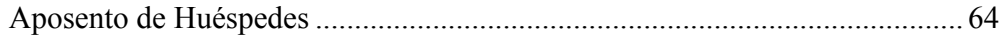

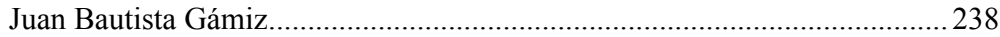

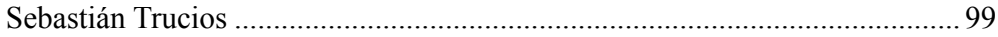

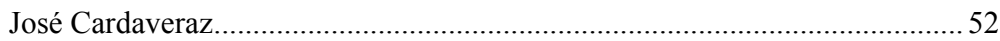

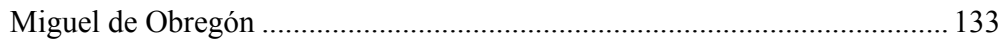

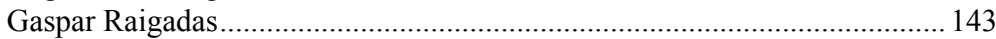

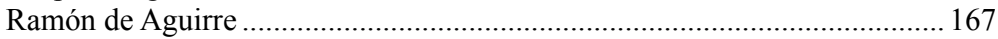

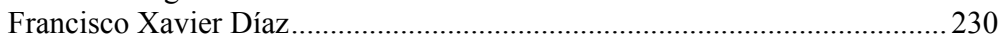

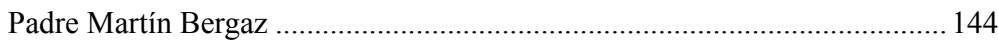

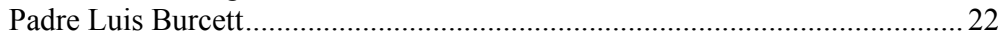

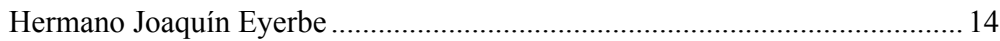

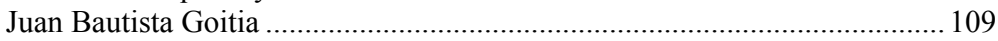

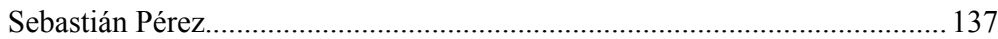

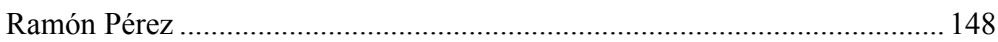

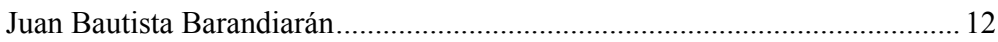

Martín de Lusarreta (Casa de Tafalla) .......................................................... 20

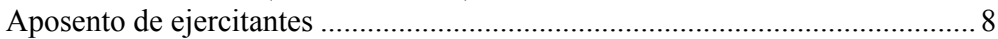

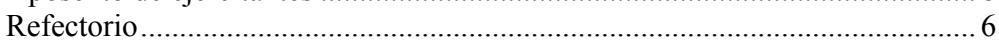

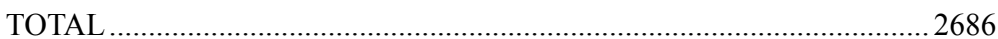

A este inventario topográfico siguió un segundo general o de la librería común. Fue realizado también por Coscuyuela siguiendo las directrices de la Real Cédula de 22 de abril de 1767; si bien se añadió una apostilla muy importante: un número que permitía identificar las fuentes por unidades temáticas. Idea que no era original del librero pamplonés. Los jesuitas tenían organizadas sus bibliotecas por facultades o temas y 
dentro de ellas por orden alfabético. Criterio que respetó Coscuyuela con exquisita escrupulosidad y que permite en buena medida reproducir el catálogo bibliográfico tal como lo tenían los jesuitas pamploneses en tiempos de la expulsión.

El resultado de su trabajo concluyó el 28 de julio de 1767, arrojando un montante de 2371 registros. El material quedó depositado «en el propio sitio que se hallaba antes de la expulsión» ${ }^{28}$, es decir en la llamada librería común, en espera de un destino definitivo. Se almacenó conjuntamente con los libros de los aposentos en 299 cajones. Todo ello suponía una cifra que superaba los 6000 volúmenes. Cantidad relativamente importantes para un colegio medio - como era el la Anunciada - que no poseía imprenta y que había hecho de sus fondos bibliográficos uno de sus íconos más representativos.

En el siguiente cuadro se ofrece una muestra de la labor llevada a cabo por Coscuyuela con los fondos de la llamada librería común.

Índice alfabético de impresos de la librería y aposentos del colegio de los jesuitas de Pamplona

\section{Litera A}

Abad, (P. Agustín); Vida de don Ignacio de Loperena

Abarca, (Doña Francisca);

Octavario de San Juan Bautista

Abarca, (Petrus); Anales de Aragón

\section{Litera B}

Baeza, (P. Didacus); In Evangelia et de Christo figuratto.

Item, de la misma obra

Item, Sermones

$\begin{array}{cccccc}\mathbf{N}^{\circ} & \text { Vol. } & \text { Tam } & \text { Edición } & \text { Año } & \text { Tasa } \\ 125 & 1 & 8^{\circ} & \text { Calatayud } & 1763 & 10 \mathrm{R} \\ 117 & 1 & 8^{\circ} & \text { Zaragoza } & 1679 & 18 \mathrm{M} \\ 76 & 3 & \text { Fol. } & \text { Salamanca } & 1684 & 20 \mathrm{R}\end{array}$

$N^{\circ}$ Vol. Tam Edición Año Tasa

$\begin{array}{llllll}83 & 8 & \text { Fol. } & \text { Lugduni } & 1632 & 32 \mathrm{R}\end{array}$

$\begin{array}{llllll}160 & 12 & \text { Fol } & \text { Vallisoleti } & 1623 & 34 \mathrm{R}\end{array}$

$\begin{array}{llllll}144 & 2 & 4^{\circ} & \text { Valladolid } & 1642 & 2 \mathrm{R}\end{array}$

\section{e) Destino del material impreso}

¿Qué suerte llevó todo este material? Se trata de un largo proceso que puede dividirse en cuatro etapas llenas de vicisitudes complejas. En la primera puede decirse que los fondos permanecieron depositados en el colegio desde julio de 1767, año en que finaliza el inventario, hasta 1772, año en que oficialmente debían entregarse al

28. A.H.N. Clero, Jesuitas, legajo 822, $\mathrm{N}^{\circ} 2$. 
obispado. ¿Qué pasó en ese tiempo? Inicialmente los fondos pamploneses no podían destinarse ni a universidad de nueva creación ni a seminario conciliar, pues al principio la diócesis no contaba ni con una ni otra institución. Por lo tanto su destino natural era su venta para allegar fondos a la causa de la expropiación. No sabemos si esto afectó poco o mucho a los libros pamploneses. El caso es que la venta de libros jesuíticos se paralizó a nivel nacional por una Real Orden, de 2 de mayo de 1769, que prescribía suspender la venta de libros de las casas de los regulares expulsos, «cuidando la Junta Municipal de que no se extravíen libros, que se mantengan en buena custodia y en parajes que no sean húmedos, ni expuestos a corrupción, para disponer de ellos a favor de Universidades y Casas de Estudios según lo que resultare de las aplicaciones de los colegios ${ }^{29}$.

Hasta aquí una primera etapa. Posteriormente, el 17 de diciembre de 1770, el Reglamento, diseñado por Manuel Ventura de Figueroa, colector general interino de expolios y vacantes, establecía que las librerías de los jesuitas expulsos se entregaran a los prelados para uso público de sus diocesanos. La medida fue comunicada al obispo de Pamplona, Irigoyen y Dutari, el 17 de febrero de $1771^{30}$. Pero las reclamaciones posteriores, hechas - como ya apuntamos - por Aranda y Campomanes al Reglamento de Ventura Figueroa, intentando dirigir los fondos a las universidades y evitar que los papeles manuscritos pasaran a los prelados, retrasaron su ejecución hasta la aprobación definitiva de la Real Provisión de 2 de mayo de 1772. Ésta prescribía con toda claridad que los papeles manuscritos se trasladasen a Madrid y las bibliotecas se entregaran con la máxima celeridad a las universidades de nueva creación y a los prelados para uso público de sus diocesanos. En el ínterin, había que velar por la conservación los libros y a tal efecto, el 1 de agosto de 1771, los Señores del Consejo dieron una Real Provisión en la que se prescribía que «las librerías que no estén ya destinadas (...) conviene se limpien y conserven con especial diligencia mientras se va acordando su destino (...) en inteligencia de que las Juntas Municipales respectivas serán responsables del daño que resulte por su omisión» ${ }^{31}$.

La tercera etapa comienza precisamente el 20 de mayo de 1772, fecha en que la Junta Municipal de Temporalidades pamplonesa acusó recibo de la citada Real Provisión de 2 de mayo de ese mismo año sobre entrega de bibliotecas. Tres días después se iniciaban los trámites formándose una comisión mixta Junta de Temporalidades y Diócesis. Estaba compuesta por José Javier de Gainza, en representación de la Junta Municipal de Temporalidades; Juan Miguel de Echenique, vicario general, en representación del obispo; y el administrador general de las temporalidades. El 4 de junio acordaron que las gestiones se iniciasen el 10 de junio, a las tres de la tarde, en el antiguo colegio de la Anunciada. Siendo Benito Coscuyuela, en atención a sus anteriores servicios, quien de nuevo se responsabilizaría de inventariar la entrega definitiva al

29. Colección general de providencias.... Parte II, pág. 141.

30. Archivo Municipal de Pamplona. Asuntos eclesiásticos, obispado, legajo 1, No 91.

31. Colección general de providencias...Parte IV, pág. 19. 
obispado, ayudándole en su tarea los amanuenses latinos Rafael Castillo y Manuel Ibiricu. La tarea duró del 10 de junio al 26 inclusive, «con exclusión de los trece, catorce, dieciocho, veintiuno y veinticuatro por festivos, y continuándose los veintisiete, veintiocho, y veintinueve de julio de mil setecientos setenta y dos» ${ }^{32}$.

El trabajo de Coscuyuela no concluyó en un nuevo inventario alfabético. Éste ya había sido hecho en 1767. El librero se limitó a depositar, sin una referencia bibliográfica completa, los libros en nuevos cajones, a clasificarlos según un cierto orden temático, computar el número de ediciones, su tamaño y sus volúmenes. El resultado fue un inventario tosco, desigual, con errores de trascripción manifiestos, incompleto y escasamente válido para identificar bibliográficamente los libros. Los siguientes ejemplos son fiel reflejo del proceso:

Cajón 25

- Obras de Fray Luis de Granada

Tamaño Fol.

Cajón 37

- Institutiones, societatis iesu.

- Galucio, de Vello belgico

- Gualterio Tabula Cronografía

- Acta santi Ignattii.
Tamaño

Fol.

Fol.

Fol.

Fol.
Volúmenes

27

Volúmenes

2

2

1

1

El trabajo de Coscuyuela tuvo dos partes. En una primera se computaron los libros que pertenecía a la antigua librería común del colegio y que estaban depositados en dicha sala. Se almacenaron en 153 cajones que contenían 1524 títulos. La segunda fase se centró en computar los libros que estaban depositados «en la capilla, aposentos, tránsitos, cajones y líneas». Su resultado supuso 2533 ediciones, que unidas a las 1524 anteriores arroja un total de 4057 títulos. Guarismos muy parecidos al global de registros computados en los inventarios de 1767.

La cuarta fase de este largo proceso se inicia precisamente con la conclusión, el 29 de julio de 1772, del nuevo inventario de Benito Coscuyuela y sus dificultades para ser entregado al obispado. Un proceso que exigía el visto bueno de la Junta Central de Temporalidades y éste asombrosamente no se firmó hasta el 5 de marzo del año siguiente. La disposición prescribía expresamente:

«Que las Librerías existentes en todas las casas, colegios y residencias que fueron de los Regulares de la Compañía, aplicadas según la Real Provisión de dos de Mayo del mismo año, se conduzcan a las casas o parajes que señalen los diocesanos, y agraciados, por cuenta de los frutos y rentas de Temporalidades» ${ }^{33}$.

Incomprensiblemente la orden no se comunicó en tiempo y forma debido a la Junta de Temporalidades de Pamplona, por lo que difícilmente pudo ejecutarse la entrega. Don Gonzalo Muñoz de Torres, miembro de la Junta Provincial de Temporalidades y regente del Consejo Real, encargado de hacerlo, retrasó la comunicación sin que

32. Archivo Diocesano de Pamplona [en adelante A.D.P.]. Caja 277, N 4. Parte final. 33. A.H.N., Clero, Jesuitas, legajo 822 
se sepan los motivos. A tal grado llegó el retraso que, el 12 de junio de 1773, desde Madrid se solicitaban razones del mismo. La Junta Municipal, desconocedora del tema, hizo averiguaciones, pero no se enteró hasta el 25 de junio. En esa fecha el Sr. Muñoz de Torres, con motivo de su jubilación, entregaba al obispo Irigoyen la carta de 5 de marzo, ratificando el visto bueno de la entrega ${ }^{34}$.

Conocidas estas circunstancias por la Junta Municipal, ésta comunicó a Madrid, el tres de julio, los motivos del retraso, comprometiéndose inmediatamente a arbitrar con urgencia las medidas pertinentes ${ }^{35}$. Asombrosamente las promesas de inmediatez volvieron a dilatarse en el tiempo, concretamente hasta el 9 de agosto de 1774, fecha en que la Junta firmaba un auto por el que nombraba a don Manuel Galdeano representante municipal para efectuar la entrega de las librerías jesuíticas al obispo baztanés Irigoyen y Dutari. Éste, enterado del acuerdo, nombró por representante episcopal a su mayordomo Miguel de Aldereguía. Y ambos acordaron efectuar la entrega, como así ocurrió, el 14 de agosto de 1774, según consta en el recibo de entrega de recepción de libros, firmado por Ramón Goñi, capellán del obispo Irigoyen $^{36}$.

\section{f) Destino definitivo de la biblioteca}

A partir de esa fecha, la antigua biblioteca de los jesuitas expulsos se ubicó en dependencias del palacio episcopal y pasó a formar parte del recién fundado Seminario Episcopal de San Agustín. A partir de 1777 también sirvió de biblioteca para el recién fundado Seminario Conciliar de San Miguel, que junto con el anterior estaban inicialmente anejos al palacio episcopal. En un documento fechado el 11 de junio de 1801, el entonces obispo de la diócesis, don Lorenzo Igual de Soria, comunicaba a Carlos IV que la librería de los jesuitas expulsos, sita en el palacio episcopal, estaba destinada para biblioteca de los dos seminarios. El 4 de mayo de 1784, la Junta del Conciliar acordó fundar una biblioteca exclusiva del Seminario, destinando al efecto una cantidad anual de fondos ${ }^{37}$. La biblioteca del palacio episcopal era sólo un complemento de la misma. Sin embargo, en tiempos del obispo Severo Andriani, al remozar el Seminario Conciliar, entre 1834-1836, se decidió ampliar su biblioteca, destinando al efecto fondos tanto de la biblioteca privada del prelado como muchos otros de la antigua librería de los jesuitas expulsos ${ }^{38}$.

Con el paso del tiempo, la mayor parte de estos libros pasaron definitivamente al Seminario y actualmente una parte importante de los mismos puede verse en los anaqueles de la biblioteca del Seminario Conciliar de San Miguel. No debe pensarse, sin embargo, que todos los libros de los jesuitas expulsos pasaron al palacio episcopal o al seminario. Muchos de ellos se perdieron, quizá, de forma voluntaria. Un dato signifi-

\footnotetext{
34. A.H.N., Clero, Jesuitas, legajo 822

35. A.D.P. Caja 277, $N^{\circ}$ 4. Parte inicial.

36. A.D.P. Caja 277, $N^{\circ}$ 4. Parte final.

37. Biblioteca del Seminario Conciliar: Libro de Autos y Acuerdos del Seminario. Junta 4 de mayo

38. Perez GoyenA, Antonio: «Efemérides del Seminario», La Avalancha, 1937, p. 372.
} 
cativo se encuentra en la obra intitulada: Colla... Patrum Opus Ioannis Eremitae, qui et Cassianus dicitur... Lugduni, 1542. En ella puede leerse la siguiente advertencia: «Este libro y los que se encuentran con este título de los jesuitas de Pamplona se descubrieron en su colegio de esta ciudad, tabicados, y se dieron a cestas a varios sujetos, año de 1810. Y uno de ellos me los alargó, y los usó, siempre dispuesto a restituir a quien pertenezca. Habitando los franceses dicho Colegio (ahora Seminario Episcopal) se descubrieron, y los mismos albañiles los dieron a quien querían recibirlos. Y los de las librerías de otros religiosos se emplearon en cartuchos ${ }^{39}$.

39. Perez GoyenA, Antonio: «La biblioteca del antiguo colegio de jesuitas de Pamplona», La Avalancha, $1929, \mathrm{~N}^{\circ} 35$, p. 69. 